\title{
Acute kidney injury and regional abdominal perfusion during neonatal aortic arch reconstruction
}

\author{
Satish K. Rajagopal, MD, ${ }^{\text {a,c }}$ Sitaram M. Emani, MD, ${ }^{\text {,cc }}$ Nathalie Roy, MD, ${ }^{\mathrm{b}}$ Lauren Westgate, RN, \\ CPNP, ${ }^{\mathrm{a}}$ and Emile A. Bacha, MD ${ }^{\mathrm{b}, \mathrm{c}}$
}

Objective: Our objective was to determine whether regional visceral perfusion during neonatal aortic arch reconstruction attenuates postoperative acute kidney injury.

\begin{abstract}
Methods: A technique to provide simultaneous perfusion to the brain and viscera during aortic arch reconstruction in neonates was developed and applied (multisite perfusion). The effect of the technique on postoperative renal function was assessed by comparing the incidence of acute kidney injury in neonates undergoing multisite perfusion to a control group of neonates who underwent aortic arch reconstruction with regional cerebral perfusion alone.
\end{abstract}

\begin{abstract}
Results: Thirteen neonates underwent multisite perfusion during procedures involving reconstruction of the aortic arch. Twenty-four neonates who underwent similar procedures with regional cerebral perfusion alone were selected as controls. The incidence of acute kidney injury in those undergoing multisite perfusion was $8 \%$ $(\mathrm{n}=1)$, compared with $50 \%(\mathrm{n}=12)$ in the control group $(P=.01)$. The median percentage change in estimated creatinine clearance was $0(-33$ to +60$)$ in the multisite perfusion group, compared with $-29(-50$ to +14$)$ in the control group $(P<.01)$. Patients in the multisite perfusion group were less frequently exposed to preoperative nephrotoxins and intraoperative aprotinin and had a higher prevalence of preoperative comorbidity, a shorter duration of regional cerebral perfusion, and a longer length of stay in the intensive care unit.
\end{abstract}

Conclusions: Acute kidney injury is common after reconstruction of the aortic arch in neonates. By providing direct visceral perfusion during surgery, this simple multisite perfusion technique may ameliorate acute kidney injury in these neonates. Further investigation of this technique is warranted. (J Thorac Cardiovasc Surg 2010;140:453-8)

Acute kidney injury (AKI) after surgery for congenital heart disease performed with cardiopulmonary bypass (CPB) is common and results in increased morbidity and mortality. ${ }^{1,2}$ The use of circulatory arrest with deep hypothermia during repair of complex aortic arch obstruction in neonates offers the advantage of a bloodless and unobstructed surgical field at the expense of compounding the endorgan injury initiated by CPB. The risk of neurologic injury during circulatory arrest prompted several investigators to develop regional cerebral perfusion (RCP) techniques to minimize the period of cerebral circulatory arrest and resulting neurologic injury. ${ }^{3-5}$

Accumulating data from adults and children suggest that AKI is a frequent complication of circulatory arrest with

From the Departments of Cardiology ${ }^{\mathrm{a}}$ and Cardiac Surgery, ${ }^{\mathrm{b}}$ Children's Hospital Boston, and Harvard Medical School, ${ }^{\mathrm{c}}$ Boston, Mass.

All work was performed in the Children's Hospital Boston, Boston, Mass.

Financial support provided by the Bertelson Critical Care Research Fund.

Disclosures: None.

Received for publication Sept 29, 2009; revisions received Jan 19, 2010; accepted for publication March 21, 2010; available ahead of print May 6, 2010.

Address for reprints: Satish K. Rajagopal, MD, Department of Cardiology, Children's Hospital, Boston, 300 Longwood Ave, Boston, MA 02115 (E-mail: Satish.

Rajagopal@Cardio.Chboston.org).

0022-5223/\$36.00

Copyright (C) 2010 by The American Association for Thoracic Surgery

doi:10.1016/j.jtcvs.2010.03.034 deep hypothermia, despite the reduction in renal metabolic demand related to hypothermia. ${ }^{6-8}$ To reduce the potential for renal ischemia during neonatal aortic arch reconstruction, we developed and used a technique to provide simultaneous regional visceral and cerebral perfusion. We hypothesized that providing regional visceral perfusion during procedures involving complex aortic arch reconstructions in neonates would decrease the rate of postoperative AKI. We assessed the efficacy of the new technique by comparing the incidence of AKI after neonatal aortic arch surgery performed with multisite perfusion (MSP) with that in recent historic controls undergoing repair with $\mathrm{RCP}$ alone.

\section{METHODS}

\section{Enrollment Criteria}

Thirteen neonates underwent neonatal aortic arch reconstruction using MSP (group 1). The aortic arch repair was in addition to the following procedures: ventricular septal defect (VSD) closure $(n=6)$, stage I Sano operation $(\mathrm{n}=5)$, pulmonary artery banding $(\mathrm{n}=1)$, and pulmonary artery banding with mitral valvotomy $(n=1)$. These 13 procedures were performed by 2 congenital heart surgeons over a 7-month period in 2009 .

Twenty-four consecutive control patients (12 having stage I Sano procedures and 12 having relief of aortic arch obstruction with VSD repairs) were used for comparison in this case-control study (group 2). These 24 procedures were performed by 4 congenital heart surgeons from 2007 through 2009. Three otherwise eligible patients were excluded from the control group because the need for mechanical support of the circulation with an 


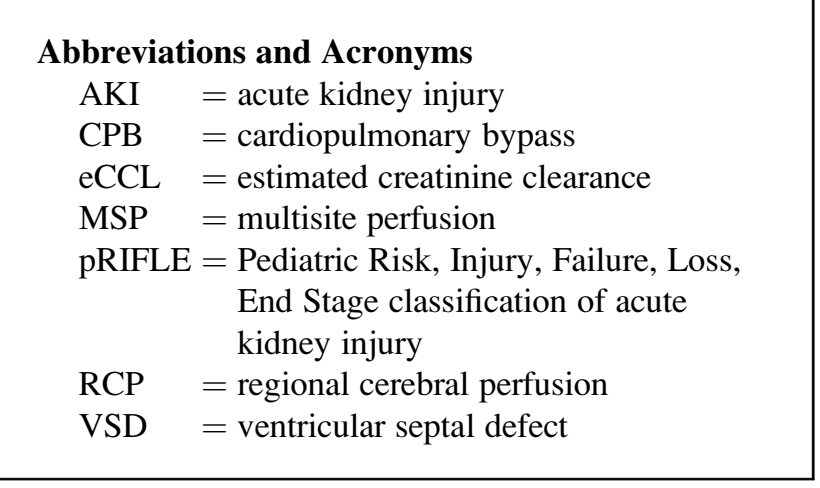

extracorporeal membrane oxygenator within 72 hours of surgery obfuscated their renal function. Only those procedures using RCP were selected as controls to account for the low-grade somatic perfusion provided during RCP. ${ }^{9}$ Of the 37 patients in this study, 35 were discharged home and 2 are convalescing in the hospital. This study was approved by the institutional review board of the Children's Hospital, Boston. Owing to the retrospective nature of the data collection, the requirement for informed consent was waived.

\section{Surgical Technique}

The standard technical approaches to these lesions were used, with minor modifications. All procedures were performed through a median sternotomy. Cerebral perfusion was achieved by cannulating a polytetrafluoroethylene tube graft sewn end to side onto the innominate artery. Visceral perfusion was provided through a $3 \mathrm{~F} 3-\mathrm{cm}$ femoral arterial catheter $(\mathrm{n}=9)$ or $3.5 \mathrm{~F} 10-\mathrm{cm}$ umbilical arterial catheter $(\mathrm{n}=4)$. Selective coronary perfusion was provided through a standard cardioplegia cannula placed into the ascending aorta $(n=10)$. These 3 cannulas were connected to the arterial perfusion limb of the CPB circuit. Venous drainage was obtained by single or dual venous cannulation. $\mathrm{CPB}$ was initiated through the innominate artery shunt, and moderate $(n=9)$ or deep $(n=4)$ hypothermia was induced. The left side of the heart was vented with a cannula placed through the right upper pulmonary vein. MSP was initiated by isolation of the hypoplastic aortic arch using tourniquets and clamps. CPB flow through the regional cannulas was decreased to 80 to $100 \mathrm{ml} \cdot \mathrm{kg}^{-1} \cdot \mathrm{min}^{-1}$. Circulatory arrest with deep hypothermia was performed for delivery of cardioplegic solution through the innominate artery shunt with clamping of the transverse aorta in a subset of patients. Patients undergoing selective coronary perfusion (typically those with normal-sized aortic roots) had a clamp placed at the level of the sinotubular junction, allowing the decompressed heart to beat during aortic arch repair. The electrocardiogram was monitored carefully during this period for any signs of ischemia.

\section{Definitions}

The primary outcome for the study was the development of AKI within 72 hours of surgery. The immediate preoperative estimated creatinine clearance (eCCL) and the 72-hour postoperative nadir eCCL were used to calculate the percent change in renal function. The percent change in renal function was also determined using the immediate preoperative eCCL and the mean 72-hour postoperative eCCL. In accordance with the Pediatric Risk, Injury, Failure, Loss, End Stage classification of acute kidney injury (pRIFLE) AKI staging system, a greater than $25 \%$ decrease in the eCCL was used as the threshold to define AKI. ${ }^{10}$ Given that we characterized postoperative renal function by 2 different methods, we report the prevalence of AKI using both definitions ( $\mathrm{AKI}_{\text {postop nadir }}$ and $\mathrm{AKI}_{\text {postop mean }}$ ).

The eCCL was calculated using the Schwartz formula $(k \cdot$ height $[\mathrm{cm}] /$ plasma creatinine $[\mathrm{mg} / \mathrm{dL}])$. The constant $k$ was 0.33 for infants born at less than 38 weeks' gestation and 0.45 for those born at or after 38 weeks' ges-
TABLE 1. Baseline demographics of the study cohort

\begin{tabular}{lccc}
\hline \multicolumn{1}{c}{ Variables } & $\begin{array}{c}\text { MSP } \\
(\mathbf{n}=\mathbf{1 3})\end{array}$ & $\begin{array}{c}\text { RCP only } \\
(\mathbf{n}=\mathbf{2 4})\end{array}$ & $\boldsymbol{P}$ value \\
\hline Male & $4(31)$ & $13(54)$ & .30 \\
Weight $(\mathrm{kg})$ & $3.14(2.20-4.20)$ & $3.29(2.06-4.50)$ & .35 \\
Prematurity & $2(15)$ & $3(13)$ & 1.0 \\
Comorbidity & $7(54)$ & $4(17)$ & .03 \\
Shock & $0(0)$ & $1(4)$ & 1.0 \\
Catheterization/contrast & $1(8)$ & $4(17)$ & .64 \\
$\quad$ exposure & & & \\
Mechanical ventilation & $2(15)$ & $7(29)$ & .45 \\
Inotropes & $6(46)$ & $9(38)$ & .73 \\
Diuretics & $9(69)$ & $16(67)$ & 1.0 \\
Nephrotoxin exposure & $0(0)$ & $8(33)$ & .03 \\
Age at operation $(\mathrm{d})$ & $4(2-10)$ & $6(2-18)$ & .09 \\
Preoperative ICU & $4(2-9)$ & $4(1-7)$ & .65 \\
$\quad$ length of $\operatorname{stay}^{(\mathrm{d})}$ & & & \\
eCCL $\left(\mathrm{mL} \cdot\right.$ min $\left.^{-1} \cdot 1.73 \mathrm{~m}^{-2}\right)$ & $41(18-60)$ & $41(23-89)$ & .62 \\
\hline Dat
\end{tabular}

Data are reported as number (\%) or median (minimum-maximum). MSP, Multisite perfusion; $R C P$, retrograde cerebral perfusion; $I C U$, intensive care unit; $e C C L$, estimated creatinine clearance.

tation. ${ }^{11,12}$ The pRIFLE criteria for AKI can also be met by oliguria $(<0.5$ $\mathrm{mL} \cdot \mathrm{kg}^{-1} \cdot \mathrm{h}^{-1}$ for $\geq 8$ hours), but no patient in our study met this definition. We chose the pRIFLE criteria for AKI and not the definition recently put forth by the Society of Thoracic Surgeons and the Multi-Societal Database Committee for Pediatric and Congenital Heart Disease (doubling of preoperative creatinine) inasmuch as this definition is insensitive to clinically important derangements in renal function. ${ }^{13}$

Prematurity was defined as birth at less than 38 weeks of gestation. Shock was defined as the need for resuscitation with inotropes and/or volume expansion, with the development of brain, liver, or kidney dysfunction in the setting of a closing ductus arteriousus or a restrictive atrial septal communication. The binary categorical variable, "comorbidity," was created to account for any preoperative condition with the potential to affect the postoperative course and/or postoperative renal function (single or dysplastic kidney, genetic syndrome, major malformation, and so on). Similarly, the presence or absence of "residual anatomic disease" with the potential to affect renal function or postoperative course was abstracted from the available data (ie, residual VSD or aortic arch obstruction). Deep hypothermia was defined as an intraoperative core body temperature of less than $19^{\circ} \mathrm{C}$. The inotrope score was calculated for each hour after surgery, as follows: dopamine $\left(\mu \mathrm{g} \cdot \mathrm{kg}^{-1} \cdot \min ^{-1}\right)+$ dobutamine $\left(\mu \mathrm{g} \cdot \mathrm{kg}^{-1} \cdot \min ^{-1}\right)+$ milrinone $\cdot 10(\mu \mathrm{g}$. $\left.\mathrm{kg}^{-1} \cdot \mathrm{min}^{-1}\right)+$ epinephrine $\cdot 100\left(\mu \mathrm{g} \cdot \mathrm{kg}^{-1} \cdot \mathrm{min}^{-1}\right){ }^{14}$ The peak inotrope score for each postoperative day was then recorded. The day of surgery was postoperative day 0 .

\section{Statistical Analysis}

SPSS version 15.0 software (SPSS, Inc, Chicago, Ill) was used for data analysis. Continuous, nonnormally distributed data were compared by the Wilcoxon rank sum test, and categorical data were analyzed by Fisher's exact test.

\section{RESULTS}

The baseline demographics of the 2 groups were statistically similar, with some notable exceptions (Table 1). A greater percentage of patients undergoing MSP had comorbid conditions at the time surgery compared with controls $(54 \%$ vs $17 \%)$. The most common comorbidities in both groups were recognized genetic syndromes and gross 
anomalies of fetal development, such as the kidney dysplasia found in 2 patients undergoing MSP. In addition, a smaller percentage of patients undergoing MSP were exposed to preoperative nephrotoxins than those in the control group $(0 \%$ vs $33 \%)$. Despite the difference in nephrotoxin exposure between the 2 groups, the preoperative eCCL in both groups was $41 \mathrm{~mL} \cdot \min ^{-1} \cdot 1.73 \mathrm{~m}^{-2}$. The difference in nephrotoxin exposure is explained by a recent shift away from the use of gentamicin, in favor of other antibiotics, while awaiting negative cultures in those neonates with risk factors for infection.

Relevant intraoperative details are presented in Table 2. There were no statistically significant differences in hematocrit nadir, peak plasma lactate concentration, urine output, excessive bleeding, or rates of delayed sternal closure. Although there were no differences in CPB or aortic crossclamp times, the median RCP time was shorter in the MSP group than in controls (34 vs 43 minutes, respectively).

Intraoperative aprotinin infusions were used less frequently in those undergoing MSP than in the control group $(0 \%$ vs $29 \%)$. In our institution, aprotinin was used routinely during operations in neonates with complex congenital heart disease until the release of a Food and Drug Administration MedWatch alert in May of 2008 warned of increased mortality rates after its use in adult cardiac surgery. Inasmuch as aprotinin was no longer available as an antifibrinolytic, the use of tranexamic acid increased, resulting in a statistically significant difference between groups 1 and $2(92 \%$ vs $21 \%)$.

Although not reaching statistical significance, a higher rate of residual anatomic disease after surgery was observed in the group of patients undergoing MSP compared with controls $(31 \%$ vs $8 \%)$. In the MSP group, 2 patients had moderate left-to-right shunting across residual complex apical muscular VSDs and 2 had pulmonary artery stenoses requiring combined balloon angioplasty and stent placement on postoperative days 8 and 54. No patient in the MSP group had recurrent aortic arch obstruction. Of the 2 patients with residual disease in the control group, 1 had a residual muscular VSD and the other had residual aortic arch obstruction requiring balloon angioplasty. None of the residual VSDs observed in this study required intervention.

Postoperative hemodynamic measurements (Table 3) were similar in the 2 groups, although peak central venous pressure on postoperative day 0 was higher in the group undergoing MSP than in the control group (12 vs $11 \mathrm{~mm} \mathrm{Hg}$ ). There were trends toward lower nadir mean arterial blood pressure and a narrower difference between arterial and mixed venous saturations in the MSP group on postoperative days 2 and 3 . There was also a trend toward more frequent blood transfusions and a higher peak 72-hour postoperative inotrope score in the MSP group compared with the control group. Patients in the MSP group remained in the cardiac intensive care unit for a longer period than
TABLE 2. Intraoperative variables

\begin{tabular}{|c|c|c|c|}
\hline Variable & $\begin{array}{c}\text { MSP } \\
(\mathbf{n}=\mathbf{1 3})\end{array}$ & $\begin{array}{c}\text { RCP only } \\
(\mathbf{n}=\mathbf{2 4})\end{array}$ & $P$ value \\
\hline Procedure & & & .73 \\
\hline $\begin{array}{l}\text { Stage I with Sano } \\
\text { modification }\end{array}$ & $5(39)$ & $12(50)$ & \\
\hline $\begin{array}{l}\text { Aortic arch reconstruction } \\
\text { with additional procedure }\end{array}$ & $8(62)$ & $12(50)$ & \\
\hline \multicolumn{4}{|l|}{ Perfusion times (min) } \\
\hline CPB time & $142(60-185)$ & $139(110-254)$ & .99 \\
\hline Cross clamp time & $66(0-115)$ & $60(22-125)$ & .76 \\
\hline Circulatory arrest time & $0(0-32)$ & $3(0-46)$ & .40 \\
\hline RCP time & $34(14-54)$ & $43(19-68)$ & .03 \\
\hline $\begin{array}{l}\text { Regional abdominal } \\
\text { perfusion time }\end{array}$ & $34(14-54)$ & NA & NA \\
\hline Temperature nadir $\left({ }^{\circ} \mathrm{C}\right)$ & $26(14.7-32)$ & $17.8(13.2-32)$ & .26 \\
\hline Circulation arrested & $4(31)$ & $12(50)$ & .32 \\
\hline Hematocrit nadir (g/dL) & $29.0(27.0-34.0)$ & $29.0(22.0-32.0)$ & .95 \\
\hline $\begin{array}{r}\text { Peak intraoperative } \\
\text { lactate }(\mathrm{mmol} / \mathrm{L})\end{array}$ & $6.3(2.7-8.8)$ & $6.0(2.7-12.6)$ & .63 \\
\hline Aprotinin & $0(0)$ & $7(29)$ & .04 \\
\hline Tranexamic acid & $12(92)$ & $5(21)$ & $<.01$ \\
\hline $\begin{array}{l}\text { Urine output } \\
\qquad\left(\mathrm{mL} \cdot \mathrm{kg}^{-1} \cdot \mathrm{h}^{-1}\right)^{*}\end{array}$ & $2.3(1.1-6.3)$ & $3.1(.8-11.6)$ & .52 \\
\hline Delayed sternal closure & $10(77)$ & $14(58)$ & .31 \\
\hline Peritoneal drain placement & $0(0)$ & $3(13)$ & .54 \\
\hline Residual anatomic disease & $4(31)$ & $2(8)$ & .16 \\
\hline
\end{tabular}

Data are reported as number (\%) or median (minimum - maximum). MSP, Multisite perfusion; $R C P$, retrograde cerebral perfusion; $\mathrm{CPB}$, cardiopulmonary bypass; $N A$, not applicable. Missing data: $* 16 \%$.

controls ( 9 vs 6 days). No patient in this study had necrotizing enterocolitis.

Postoperative renal function data are presented in Table 4. The median decline in eCCL (using the postoperative nadir eCCL) was $0 \%$ in the group undergoing MSP compared with $29 \%$ in the group who underwent RCP alone $(P<.01)$. Similarly, the median decline in eCCL in the control group (using the postoperative mean eCCL) was $15 \%$ compared with an increase of $15 \%$ in the group undergoing MSP $(P<.01)$. There was a trend toward both higher absolute 72-hour postoperative nadir eCCL and 72-hour postoperative mean eCCL in the group undergoing MSP compared with controls ( $37 \mathrm{vs} 30 \mathrm{~mL} \cdot \mathrm{min}^{-1} \cdot 1.73 \mathrm{~m}^{-2}$ and 48 vs 38 $\mathrm{mL} \cdot \min ^{-1} \cdot 1.73 \mathrm{~m}^{-2}$, respectively).

The threshold for $\mathrm{AKI}_{\text {postop nadir }}$ was reached in $8 \%(\mathrm{n}=1)$ of those undergoing MSP and in 50\% $(\mathrm{n}=12)$ of controls $(P=.01)$. Although not reaching statistical significance, none of the patients in the group undergoing MSP met the criteria for AKI when the 72-hour postoperative eCCL mean

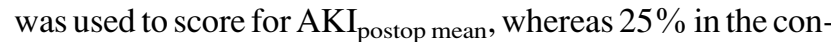
trol group did. Given the high rate of $\mathrm{AKI}_{\text {postop nadir }}$ in the control group, we analyzed the rate of $\mathrm{AKI}_{\text {postop nadir }}$ in a separate cohort of 36 neonates undergoing repair of aortic arch obstruction with VSD closure or a stage I Sano procedure at our institution in 2003. Of the 37 neonates, $18(49 \%)$ 
TABLE 3. Postoperative variables

\begin{tabular}{|c|c|c|c|}
\hline Variable & $\begin{array}{c}\text { MSP } \\
(n=13)\end{array}$ & $\begin{array}{c}\text { RCP only } \\
(n=24)\end{array}$ & $P$ value \\
\hline $\begin{array}{l}\text { Nephrotoxin exposure } \\
\quad \text { (within } 72 \mathrm{~h} \text { ) }\end{array}$ & $1(8)$ & $1(4)$ & 1.0 \\
\hline $\begin{array}{l}\text { Blood transfusion } \\
\quad \text { (within } 72 \mathrm{~h} \text { ) }\end{array}$ & $12(92)$ & $15(63)$ & .07 \\
\hline Re-exploration (within $72 \mathrm{~h}$ ) & $3(23)$ & $5(21)$ & 1.0 \\
\hline Necrotizing enterocolitis & $0(0)$ & $0(0)$ & 1.0 \\
\hline $\begin{array}{l}\text { Peak } 72 \text {-h plasma } \\
\text { lactate }(\mathrm{mmol} / \mathrm{L})\end{array}$ & $6.5(2.7-12.6)$ & $5.8(2.7-12.0)$ & .55 \\
\hline Peak 72-h inotrope score & $15(8-20)$ & $12.5(5-28)$ & .11 \\
\hline \multicolumn{4}{|l|}{ No. of diuretics } \\
\hline Day 0 & $0(0-1)$ & $0(0-1)$ & .66 \\
\hline Day 1 & $1(0-1)$ & $1(0-2)$ & .89 \\
\hline Day 2 & $1(1-2)$ & $1(1-2)$ & .80 \\
\hline Day 3 & $2(1-2)$ & $1(1-2)$ & .23 \\
\hline \multicolumn{4}{|l|}{ MAP nadir (mm Hg) } \\
\hline Day 0 & $43(32-52)$ & $45(31-62)$ & .81 \\
\hline Day 1 & $45(31-49)$ & $43(33-62)$ & .96 \\
\hline Day 2 & $41(35-50)$ & $47(34-58)$ & .08 \\
\hline Day 3 & $44(28-50)$ & $47(35-56)$ & .09 \\
\hline \multicolumn{4}{|l|}{ CVP peak $(\mathrm{mm} \mathrm{Hg})$} \\
\hline Day $0 *$ & $12(11-17)$ & $11(9-16)$ & .02 \\
\hline Day 1 & $13(9-18)$ & $13(7-20)$ & .17 \\
\hline Day $2 *$ & $13(8-15)$ & $13(7-16)$ & .31 \\
\hline Day $3 \dagger$ & $12(8-15)$ & $11(8-14)$ & 1.0 \\
\hline \multicolumn{4}{|l|}{$\begin{array}{c}\text { Peak } \mathrm{AVO}_{2} \text { saturation } \\
\text { difference }\end{array}$} \\
\hline Day $0 \ddagger$ & $37(28-50)$ & $35(25-50)$ & .54 \\
\hline Day $1 \S$ & $37(22-43)$ & $34(12-53)$ & .75 \\
\hline Day $2 \|$ & $25(24-30)$ & $28(22-40)$ & .08 \\
\hline Day 39 & $26(21-30)$ & $34(16-40)$ & .06 \\
\hline \multicolumn{4}{|l|}{$\begin{array}{l}\text { Net daily } \\
\quad \text { fluid balance }(\mathrm{mL} / \mathrm{kg})\end{array}$} \\
\hline Day 1 & $-9(-71$ to 117$)$ & $-37(-117$ to 71$)$ & .05 \\
\hline Day 2 & $-63(-133$ to 32$)$ & $-55(-275$ to 40$)$ & .78 \\
\hline Day 3\# & $-67(-191$ to -4$)$ & $-44(-112$ to 34$)$ & .31 \\
\hline \multicolumn{4}{|l|}{ Time to (d): } \\
\hline Chest closure & $3(0-7)$ & $1(0-7)$ & .08 \\
\hline Enteral feeds & $4(2-10)$ & $3(1-9)$ & .07 \\
\hline Extubation & $6(1-46)$ & $4(1-14)$ & .06 \\
\hline ICU discharge & $9(4-139)$ & $6(3-24)$ & .05 \\
\hline
\end{tabular}

Data are reported as number (\%) or median (minimum-maximum). Missing data: $* 3 \%, \dagger 11 \%, \ddagger 49 \%, \S 38 \%, \| 57 \%, \uparrow 62 \%, \# 5 \%$. MSP, Multisite perfusion; $R C P$, retrograde cerebral perfusion; $M A P$, mean arterial blood pressure; $C V P$, central venous pressure; $\mathrm{AVO}_{2}$, arteriovenous oxygen; ICU, intensive care unit.

met the criteria for $\mathrm{AKI}_{\text {postop nadir }}$ Similarly, given the skewed exposure to, and potential effects of aprotinin and preoperative nephrotoxins on changes in renal function, separate analyses were repeated after excluding those who received each of these and the results were similar (Table 5).

\section{DISCUSSION}

Over the past 3 decades, dramatic advances in surgical technique, CPB technology, and postoperative management
TABLE 4. Renal function outcomes

\begin{tabular}{|c|c|c|c|}
\hline Variable & $\begin{array}{c}\text { MSP } \\
(n=13)\end{array}$ & $\begin{array}{c}\text { RCP only } \\
(n=24) \\
\end{array}$ & $\begin{array}{c}P \\
\text { value } \\
\end{array}$ \\
\hline \multicolumn{4}{|l|}{$\begin{array}{l}\text { Urine output } \\
\qquad\left(\mathrm{mL} \cdot \mathrm{kg}^{-1} \cdot \mathrm{h}^{-1}\right)\end{array}$} \\
\hline Day 1 & $3.8(0.7-6.5)$ & $4.6(1.0-9.1)$ & .15 \\
\hline Day 2 & $7.5(2.8-9.4)$ & $6.2(2.5-16.7)$ & .62 \\
\hline Day 3 & $7.1(3.7-10.3)$ & $5.4(2.7-9.9)$ & .28 \\
\hline $\begin{array}{l}\text { Nadir 72-hour postop eCCL } \\
\quad\left(\mathrm{mL} \cdot \min ^{-1} \cdot 1.73 \mathrm{~m}^{-2}\right)\end{array}$ & $37(28-75)$ & $30(20-57)$ & .10 \\
\hline $\begin{array}{l}\text { Mean 72-hour postop eCCL } \\
\quad\left(\mathrm{mL} \cdot \mathrm{min}^{-1} \cdot 1.73 \mathrm{~m}^{-2}\right)\end{array}$ & $48(29-75)$ & $38(25-65)$ & .15 \\
\hline $\mathrm{AKI}_{\text {postop nadir }} *$ & $1(8)$ & $12(50)$ & .01 \\
\hline $\mathrm{AKI}_{\text {postop mean }} \dagger$ & $0(0)$ & $6(25)$ & .07 \\
\hline eCCL change $e_{\text {postop nadir }}(\%)^{*}$ & $0(-33$ to 60$)$ & $-29(-50$ to 14$)$ & $<.01$ \\
\hline eCCL change $e_{\text {postop mean }}(\%) \dagger$ & $15(-18$ to 64$)$ & $-15(-38$ to 42$)$ & $<.01$ \\
\hline
\end{tabular}

Data are reported as number (\%) or median (minimum-maximum). MSP, Multisite perfusion; $R C P$, retrograde cerebral perfusion; $e C C L$, estimated creatinine clearance; AKI, acute kidney injury. $*$ (nadir postop eCCL - preop eCCL)/preop eCCL. †(mean postop eCCL - preop eCCL)/preop eCCL.

have resulted in a substantial decrease in mortality and morbidity rates after surgery for congenital heart disease in neonates. Despite this, morbidity related to end-organ dysfunction resulting from inflammation and ischemia-reperfusion injury remains a significant problem. We developed a simple technique to improve visceral perfusion and tested the hypothesis that, compared with upper body regional perfusion alone, MSP with moderate or deep hypothermia is associated with decreased postoperative AKI in neonates undergoing reconstruction of the aortic arch.

Yasui and associates ${ }^{3}$ have also described a technique to provide regional visceral perfusion during repair of interrupted aortic arch. Their technique involved a separate left

TABLE 5. Subgroup analysis of renal function outcomes

\begin{tabular}{|c|c|c|c|}
\hline Variable & $\begin{array}{c}\text { MSP } \\
(n=13)\end{array}$ & $\begin{array}{c}\text { RCP only } \\
(\mathbf{n}=11)\end{array}$ & $P$ value \\
\hline \multicolumn{4}{|l|}{$\begin{array}{l}\text { Urine output } \\
\qquad\left(\mathrm{mL} \cdot \mathrm{kg}^{-1} \cdot \mathrm{h}^{-1}\right)\end{array}$} \\
\hline Day 1 & $3.8(0.7-6.5)$ & $3.6(1.0-9.1)$ & .96 \\
\hline Day 2 & $7.5(2.8-9.4)$ & $6.6(2.5-16.7)$ & .87 \\
\hline Day 3 & $7.1(3.7-0.3)$ & $6.8(2.8-8.1)$ & .53 \\
\hline $\begin{array}{l}\text { Nadir } 72 \text { hour postoperative } \\
\text { eCCL }\left(\mathrm{ml} / \mathrm{min} / 1.73 \mathrm{~m}^{2}\right)\end{array}$ & $37(28-75)$ & $26(20-41)$ & $<.01$ \\
\hline $\begin{array}{l}\text { Mean } 72 \text { hour } \\
\text { postoperative eCCL } \\
\quad\left(\mathrm{mL} \cdot \mathrm{min}^{-1} \cdot 1.73 \mathrm{~m}^{-2}\right)\end{array}$ & $48(29-75)$ & $30(27-49)$ & .02 \\
\hline $\mathrm{AKI}_{\text {postop nadir }} *$ & $1(8)$ & $7(64)$ & $<.01$ \\
\hline $\mathrm{AKI}_{\text {postop mean }} \dagger$ & $0(0)$ & $2(18)$ & .20 \\
\hline eCCL change $e_{\text {postop nadir }}(\%)^{*}$ & $0(-33$ to 60$)$ & $-33(-50$ to 14$)$ & $<.01$ \\
\hline eCCL change $e_{\text {postop mean }}(\%) \dagger$ & $15(-18$ to 64$)$ & $-14(-38$ to 42$)$ & $<.01$ \\
\hline
\end{tabular}


anterolateral thoracotomy and mobilization of the descending aorta with subsequent end-to-side anastomosis of a polytetrafluoroethylene tube graft. A Y connection was then made in the arterial limb of the bypass circuit, allowing simultaneous perfusion to the ascending and descending aorta. The same group modified this technique for use in patients undergoing the Norwood procedure. The descending aorta was accessed with an angled metal cannula via an incision in the posterior pericardium at the level of the diaphragm. ${ }^{15} \mathrm{~A}$ similar technique was also used by Sano and colleagues ${ }^{16}$ in patients undergoing modified stage I Norwood procedures. These previous studies have described techniques of regional visceral perfusion, but have not assessed the effect of lower body perfusion on the function of the kidneys or other abdominal viscera.

This study demonstrates a significantly lower incidence of AKI after neonatal aortic arch reconstructions performed with MSP compared with recent results in a control group undergoing repair with RCP only. This finding substantiates the theory that providing direct abdominal perfusion during neonatal aortic arch surgery ameliorates the renal insult imposed by ischemia and reperfusion. The high prevalence of AKI identified in the control arm of this study and the burgeoning data suggesting the important contribution of renal dysfunction to postoperative morbidity and mortality after cardiac surgery reinforce the importance of this issue. ${ }^{2,17-19}$

Importantly, we did not observe any complications that could be directly attributed to the use of this new technique. There were no clinically apparent blood vessel injuries in those who underwent visceral perfusion. We did, however, find that there was a more protracted postoperative course in the group of patients undergoing MSP as evidenced by a longer length of stay in the cardiac intensive care unit. This finding is difficult to explain, but it may relate to the substantially higher prevalence of preoperative comorbidities in the MSP group. Both genetic syndromes and structural malformations are widely known risk factors for prolonged recovery after surgery for congenital heart disease in neonates. ${ }^{20-22}$

There are several important limitations to this study. In addition to those mentioned earlier, there were other differences between the group undergoing MSP and those undergoing RCP alone. Patients in the control group were exposed to preoperative nephrotoxins and intraoperative aprotonin more frequently and had longer cerebral perfusion times. Inasmuch as this was not a randomized, controlled trial, our cases and controls were not ideally matched, leaving open the possibility of confounding by these or unrecognized factors. The small sample size of this study precluded logistic regression modeling to control for such potential confounders.

Because intraoperative and postoperative management are constantly evolving and improving, it is possible that the selection of historic, although recent, controls resulted in high baseline AKI rates, thereby exaggerating the difference between the 2 groups. It is also possible that subtle differences in regional perfusion techniques used by the attending surgeon influenced the primary outcome inasmuch as the patients in the control group were operated on by 4 different staff surgeons, whereas only 2 of them operated on the 13 patients undergoing MSP. During this pilot study, we did not systematically measure several important variables including intraoperative and postoperative renal nearinfrared spectroscopy, flow through the femoral or umbilical artery catheters, hepatic enzyme concentrations, urinary biomarkers of AKI, and intraoperative gastric mucosal carbon dioxide tension as a marker of mucosal perfusion.

In conclusion, we used a simple technique to provide simultaneous regional cerebral and visceral perfusion during neonatal aortic arch reconstruction in an attempt to ameliorate renal injury. We found a significant decrease in the rate of AKI in those undergoing MSP compared with that in control patients in whom RCP alone was used. Despite the limitations of this study, this is a promising and simple technique that warrants further investigation.

\section{References}

1. Toth-Heyn P, Drukker A, Guignard JP. The stressed neonatal kidney: from pathophysiology to clinical management of neonatal vasomotor nephropathy. Pediatr Nephrol. 2000;14:227-39.

2. Baskin E, Saygili A, Harmanci K, Agras PI, Ozdemir FN, Mercan S, et al. Acute renal failure and mortality after open-heart surgery in infants. Ren Fail. 2005;27: 557-60.

3. Yasui H, Kado H, Yonenaga K, Kawasaki S, Shiokawa Y, Kouno H, et al. Revised technique of cardiopulmonary bypass in one-stage repair of interrupted aortic arch complex. Ann Thorac Surg. 1993;55:1166-71.

4. Pigula FA, Nemoto EM, Griffith BP, Siewers RD. Regional low-flow perfusion provides cerebral circulatory support during neonatal aortic arch reconstruction. J Thorac Cardiovasc Surg. 2000;119:331-9.

5. Newburger JW, Jonas RA, Wernovsky G, Wypij D, Hickey PR, Kuban KC, et al. A comparison of the perioperative neurologic effects of hypothermic circulatory arrest versus low-flow cardiopulmonary bypass in infant heart surgery. $N$ Engl J Med. 1993;329:1057-64.

6. Dittrich S, Priesemann M, Fischer T, Boettcher W, Muller C, AlexiMeskishvili V, et al. Circulatory arrest and renal function in open-heart surgery on infants. Pediatr Cardiol. 2002;23:15-9.

7. Asfour B, Bruker B, Kehl HG, Frund S, Scheld HH. Renal insufficiency in neonates after cardiac surgery. Clin Nephrol. 1996;46:59-63.

8. Arnaoutakis GJ, Bihorac A, Martin TD, Hess PJ Jr, Klodell CT, Ejaz AA, et al. RIFLE criteria for acute kidney injury in aortic arch surgery. J Thorac Cardiovasc Surg. 2007; 134:1554-60; discussion 60-1.

9. Pigula FA, Gandhi SK, Siewers RD, Davis PJ, Webber SA, Nemoto EM. Regional low-flow perfusion provides somatic circulatory support during neonatal aortic arch surgery. Ann Thorac Surg. 2001;72:401-6; discussion 6-7.

10. Akcan-Arikan A, Zappitelli M, Loftis LL, Washburn KK, Jefferson LS Goldstein SL. Modified RIFLE criteria in critically ill children with acute kidney injury. Kidney Int. 2007;71:1028-35.

11. Schwartz GJ, Haycock GB, Edelmann CM Jr, Spitzer A. A simple estimate of glomerular filtration rate in children derived from body length and plasma creatinine. Pediatrics. 1976;58:259-63.

12. Brion LP, Fleischman AR, McCarton C, Schwartz GJ. A simple estimate of glomerular filtration rate in low birth weight infants during the first year of life: noninvasive assessment of body composition and growth. J Pediatr. 1986;109: 698-707.

13. Welke KF, Dearani JA, Ghanayem NS, Beland MJ, Shen I, Ebels T. Renal complications associated with the treatment of patients with congenital cardiac 
disease: consensus definitions from the Multi-Societal Database Committee for Pediatric and Congenital Heart Disease. Cardiol Young. 2008;18(Suppl. 2): 222-5.

14. Mou SS, Giroir BP, Molitor-Kirsch EA, Leonard SR, Nikaidoh H, Nizzi F, et al. Fresh whole blood versus reconstituted blood for pump priming in heart surgery in infants. N Engl J Med. 2004;351:1635-44.

15. Imoto Y, Kado H, Shiokawa Y, Fukae K, Yasui H. Norwood procedure without circulatory arrest. Ann Thorac Surg. 1999;68:559-61.

16. Sano S, Ishino K, Kado H, Shiokawa Y, Sakamoto K, Yokota M, et al. Outcome of right ventricle-to-pulmonary artery shunt in first-stage palliation of hypoplastic left heart syndrome: a multi-institutional study. Ann Thorac Surg. 2004;78: 1951-7; discussion 7-8.

17. Chertow GM, Levy EM, Hammermeister KE, Grover F, Daley J. Independent association between acute renal failure and mortality following cardiac surgery. Am J Med. 1998;104:343-8.
18. Lassnigg A, Schmid ER, Hiesmayr M, Falk C, Druml W, Bauer P, et al. Impact of minimal increases in serum creatinine on outcome in patients after cardiothoracic surgery: do we have to revise current definitions of acute renal failure? Crit Care Med. 2008;36:1129-37.

19. Rosner MH, Okusa MD. Acute kidney injury associated with cardiac surgery. Clin J Am Soc Nephrol. 2006;1:19-32.

20. Silberbach M, Shumaker D, Menashe V, Cobanoglu A, Morris C. Predicting hospital charge and length of stay for congenital heart disease surgery. Am J Cardiol. 1993;72:958-63.

21. Simsic JM, Coleman K, Maher KO, Cuadrado A, Kirshbom PM. Do neonates with genetic abnormalities have an increased morbidity and mortality following cardiac surgery? Congenit Heart Dis. 2009;4:160-5.

22. Stasik CN, Gelehrter S, Goldberg CS, Bove EL, Devaney EJ, Ohye RG. Current outcomes and risk factors for the Norwood procedure. J Thorac Cardiovasc Surg. 2006;131:412-7. 